\title{
Humoral and cellular immune responses in mice against secreted and somatic antigens from a Corynebacterium pseudotuberculosis attenuated strain: Immune response against a $C$. pseudotuberculosis strain
}

Vera Lúcia Costa Vale ${ }^{1,5^{*}}$, Marcos da Costa Silva ${ }^{4,5}$, Andréia Pacheco de Souza ${ }^{5}$, Soraya Castro Trindade ${ }^{3,5}$, Lília Ferreira de Moura-Costa ${ }^{2}$, Ellen Karla Nobre dos Santos-Lima ${ }^{5}$, Ivana Lucia de Oliveira Nascimento ${ }^{2,5}$, Hugo Saba Pereira Cardoso ${ }^{1}$, Edson de Jesus Marques ${ }^{1}$, Bruno Jean Adrien Paule ${ }^{5}$ and Roberto José Meyer Nascimento ${ }^{2,5}$

\begin{abstract}
Background: Corynebacterium pseudotuberculosis is the etiologic agent of caseous lymphadenitis (CL), a chronic disease that affects goats and sheep. $\mathrm{CL}$ is characterized by the formation of granulomas in lymph nodes and other organs, such as the lungs and liver. Current knowledge of $\mathrm{CL}$ pathogenesis indicates that the induction of humoral and cellular immune responses are fundamental to disease control. The aim of this study was to evaluate the humoral and cellular immune responses in BALB/C mice inoculated with a C. pseudotuberculosis strain isolated in the state of Bahia, Brazil.
\end{abstract}

Results: The lymphocyte proliferation and in vitro production of IFN- $\gamma$, IL-4, IL-10, IL-12 and nitric oxide by spleen cells stimulated with secreted and somatic antigens from the studied strain were evaluated. IgG subclasses were also analyzed. Results showed a significant increase of Th1-profile cytokines after 60 days post-inoculation, as well as an important humoral response, represented by high levels of IgG2a and lgG1 against C. pseudotuberculosis.

Conclusion: The T1 strain of C. pseudotuberculosis was shown to induce humoral and cellular immune responses in $\mathrm{BALB} / \mathrm{C}$ mice, but, even at a dosage of $1 \times 10^{7} \mathrm{CFU}$, no signs of the disease were observed.

Keywords: Corynebacterium pseudotuberculosis, Cytokines, BALB/c, IgG isotypes

Abbreviations: $\mathrm{CL}$, Caseous lymphadenitis; NO, Nitric oxide; OD, Optical density; Se, Secreted antigen; So, Somatic antigen.

\footnotetext{
* Correspondence: vvale@uneb.br

'Department of Exact and Earth Sciences, State University of Bahia, Campus

II, Alagoinhas, BA CEP 48110-100, Brazil

5 Immunology and Molecular Biology Laboratory, Health Sciences Institute,

Federal University of Bahia, Av. Reitor Miguel Calmon s/n, Vale do Canela,

Salvador, BA CEP 40110-100, Brazil

Full list of author information is available at the end of the article
} 


\section{Background}

Caseous lymphadenitis (CL) is a chronic disease caused by Corynebacterium pseudotuberculosis that mainly affects small ruminants. Despite the economic $[1,2]$ and zoonotic [3] relevance of CL, a satisfactory vaccine model has not been developed $[4,5]$.

C. pseudotuberculosis is a facultative intracellular pathogen that can persist inside macrophages and stimulate the formation of granulomas $[6,7]$. This species is distributed worldwide, but has the most severe economic impacts in Oceania, Africa and South America [8].

The pathogenesis of CL in mice was demonstrated by monitoring the progression of lesions in the skin and viscera of infected animals [9]. Moreover, the physiology, pathogenicity and virulence mechanisms of $C$. pseudotuberculosis strains have been elucidated using genomics $[8,10]$, transcriptomics and proteomics methodologies $[11,12]$.

The immune response against $C$. pseudotuberculosis has a well-known humoral component and involves a complex cellular mechanism against secreted and somatic bacterial antigens [13-15].

The cytokines Tumor necrosis factor- $\alpha$ (TNF- $\alpha$ ) and interferon- $\gamma$ (IFN- $\gamma$ ) are important to mount an immune response in mice as well as sheep, whether naturally infected or inoculated with C. pseudotuberculosis [16-19]. It is known that, with respect to Mycobacterium tuberculosis, a microorganism largely phylogenetically similar to C. pseudotuberculosis, these cytokines play a major role in susceptibility and regulation of associated lesions in mice [20].

El-Enbaawy et al. (2005) [21] demonstrated that antigens obtained from a $C$. pseudotuberculosis strain isolated from a naturally infected sheep, specifically a toxoid associated with bacterin, induce the production of IFN- $\gamma$, as well as elicit a humoral immune response in $\mathrm{BALB} / \mathrm{c}$ mice. The present study employed a naturally attenuated strain of C. pseudotuberculosis, denominated $\mathrm{T} 1$, isolated from a granuloma taken from a goat in a rural region of the state of Bahia, located in northeastern Brazil. Studies previously conducted with this strain show that it grows quickly in BHI broth medium, when compared to other strains, but is incapable of inducing disease in goats [22-24].

The present study characterized the immune response in $\mathrm{BALB} / \mathrm{c}$ mice, considering five animals per group, against antigens derived from the T1 strain of $C$. pseudotuberculosis. This murine model was chosen because of impaired IFN- $\gamma$ production in response to antigens derived from $M$. tuberculosis, which is very closely related to C. pseudotuberculosis [25]. The proliferation of spleen cells was investigated, as well as the production of cytokines, nitric oxide (NO) and serum IgG subclasses to expand the understanding of humoral and cellular immune responses against this strain, which may represent an ideal vaccine candidate against this disease.

\section{Results}

To determine the optimal inoculation dosage, four different infection dosages $\left(5 \times 10^{5}, 1 \times 10^{6}, 5 \times 10^{6}\right.$ and $1 \times 10^{7}$ CFU) of the T1 C. pseudotuberculosis strain were tested in BALB/c mice. ELISA results showed higher IgG levels in mice infected with the two higher dosages in comparison to the two lower levels tested $(P<0.001)$ (Fig. 1a). No significant differences in IgG levels were seen between the groups inoculated with $5 \times 10^{6}$ and $1 \times 10^{7} \mathrm{CFU}$, nor in the groups inoculated with $5 \times 10^{5}$ and $1 \times 10^{6} \mathrm{CFU}$. At 120 days post-infection, none of the animals presented any evidence of lesions characteristic of the disease under clinical examination or necropsy. Because the $1 \times 10^{7}$ CFU dosage was not observed to induce lesions, this experimental protocol was used to evaluate the production of IgG subclasses and cytokines.

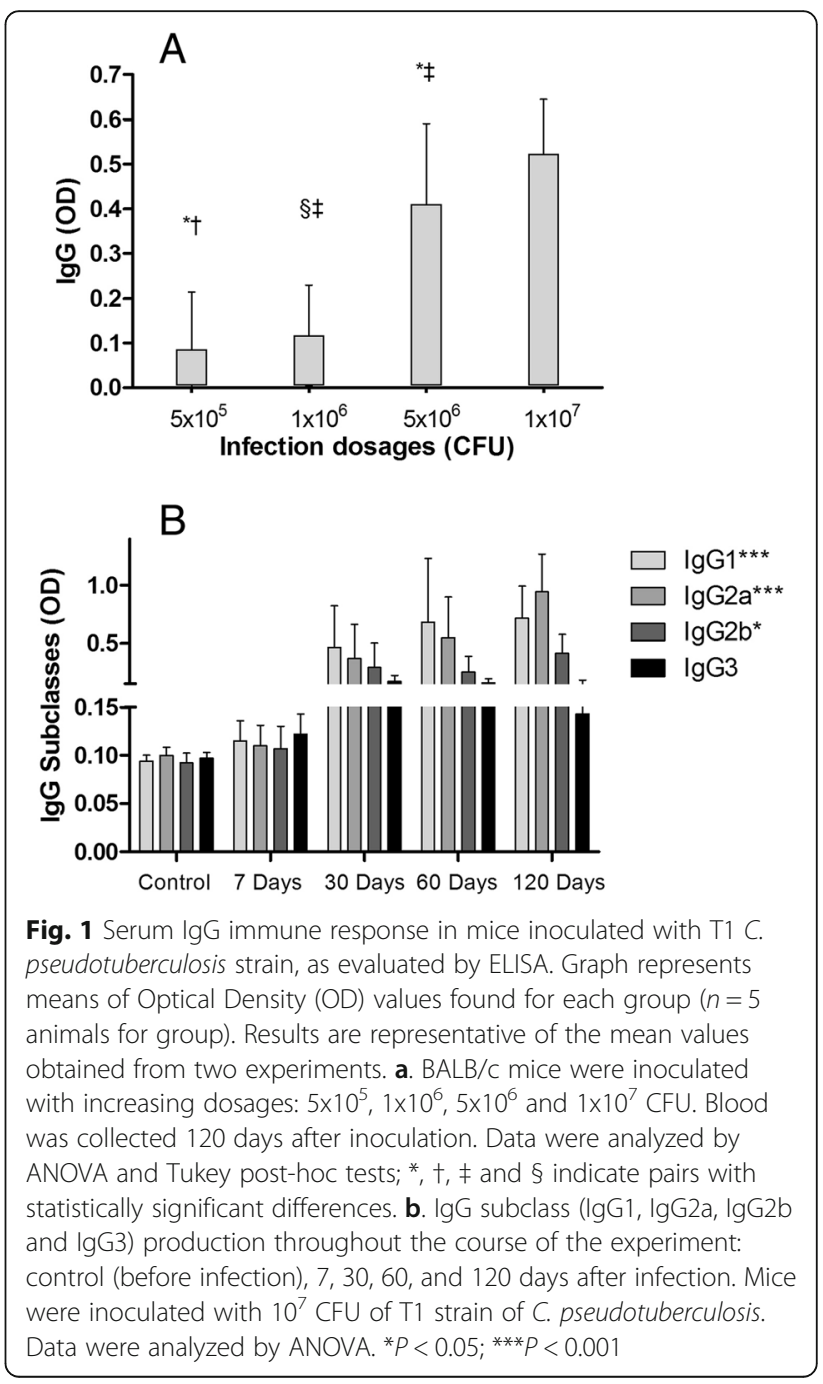


Analysis of the humoral immune response against T1 C. pseudotuberculosis revealed that IgG2a production gradually increased over time, being the predominant IgG subclass at 120 days after infection $(P<0.001)$. A significant increase in IgG1 levels $(P<0.001)$ was also observed, and a discrete, yet still statistically significant, increase of IgG2b $(P<0.05)$ was seen. No statistically significant differences in IgG3 levels were detected over the course of experimentation. Control group results are representative of the mean OD readings obtained from five animals before infection (Fig. 1b).

With respect to spleen cell response to antigenic stimuli, a significant lymphoproliferative response, expressed as SI, was observed after stimulation with secreted antigen (Se) $(p<0.05)$ at 60 days post-infection in comparison to 7 and 30 days (Fig. 2). Stimulation with Se provoked a significant difference in SI in comparison to So at 60 days after inoculation.

In vitro production of interleukin-12 (IL-12) by spleen cells after stimulation with So or Se antigens is shown in Fig. 3a. Cell stimulated with both antigens had higher IL-12 concentrations at 60 and 120 days post-infection in comparison to controls $(p<0.05)$.

No differences were seen in IFN- $\gamma$ concentration in the antigen-stimulated culture supernatants in comparison to controls at seven and 30 days post-infection, but there significant increases were observed at 60 days $(\mathrm{p}<0.05)$ and 120 days $(p<0.05)$ post infection. So also induced a higher and statistical significant INF- $\gamma$ production, when compared to Se stimulation (Fig. 3b) at both of these times points.

With respect to in vitro interleukin-10 (IL-10) production, a significant statistical difference was observed in So-stimulated cells at 60 days post-inoculation $(p<0,05)$ in comparison to the previous infection times, and also

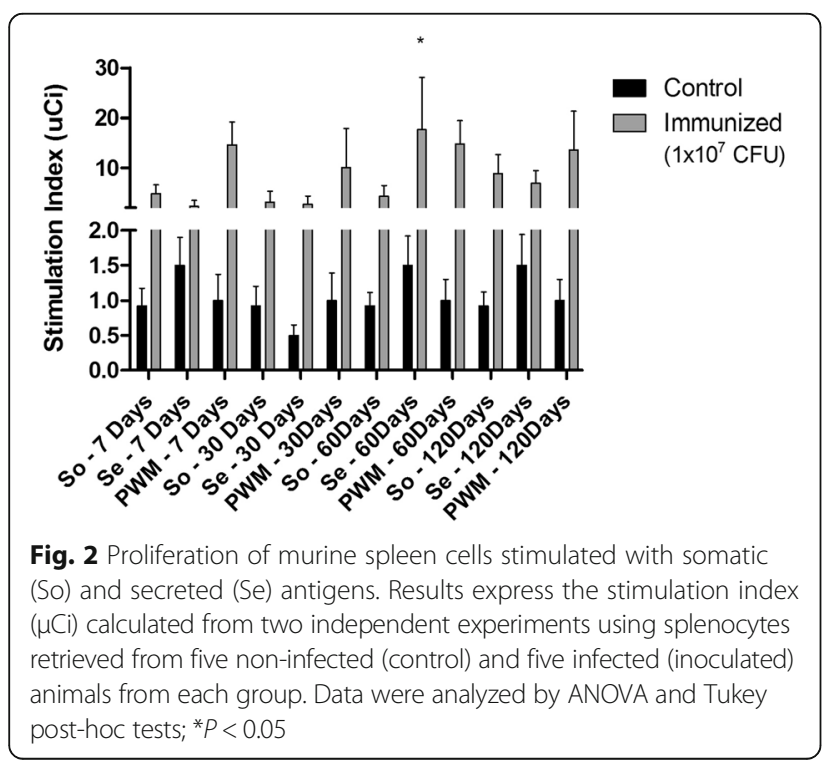

in comparison to cells stimulated with Se at this same time point. A similar situation was observed at 120 days after inoculation (Fig. 3c). In addition, cells stimulated with So induced higher levels of IL-10 than Se throughout the experiment.

Interleukin-4 (IL-4) concentrations were very low at all experiment times evaluated with respect to both antigens. However, IL-4 production by cells stimulated with So was observed to significantly increase throughout the course of investigation $(p<0.05)$, but decreased at the 120 day time point (Fig. 3d).

Nitric oxide (NO) production measured in the supernatant of cell cultures stimulated So and Se is illustrated in Fig. 4. A significant increase $(p<0.05)$ in NO levels was seen only at 120 days post-infection in comparison to controls.

NO production by cells stimulated with So was also observed to be higher in comparison to Se, with statistical significance $(p<0.05)$ at 120 days after inoculation.

\section{Discussion}

The present study found that experimental inoculations of the attenuated T1 strain of C. pseudotuberculosis at a dosage of $10^{7} \mathrm{CFU}$ did not result in lesions in BALB/c mice, even though these animals have demonstrated susceptibility to intracellular pathogens [26, 27]. Nevertheless, a previous study has shown that a wild-type strain of $C$. pseudotuberculosis was able to induce lesions at a dosage of $10^{2}$ [15].

In addition, cell cultures stimulated with $\mathrm{T} 1$ strain antigens were found to induce a proliferation of spleen cells, with secreted antigens (Se) demonstrating greater effectiveness than somatic antigens (So) two months after inoculation. A previous study showed that Se was able to enhance lymphocyte proliferation in PBMCs of an experimentally infected goat [23], which is consistent with our results. Se was found to induce a more intense proliferation than So due to the presence of phospholipase D, an exotoxin secreted by C. pseudotuberculosis at the beginning of infection to cleave the host cell membrane [28], which may cause a preeminent proliferation of B lymphocytes and elicit antibody production. Notably, lymphoproliferation in a murine model after stimulus with C. pseudotuberculosis antigens has not been described in the literature to date.

Experimental inoculation with $\mathrm{T} 1$ was observed to elicit high titers of IgG antibodies. The main IgG subclasses produced throughout the course of infection were IgG1 and IgG2a. As C. pseudotuberculosis is an intracellular pathogen that produces phospholipase $\mathrm{D}$, an exotoxin with highly immunogenic properties $[29,30]$, the production of specific immunoglobulins is crucial to neutralize phospholipase D. 


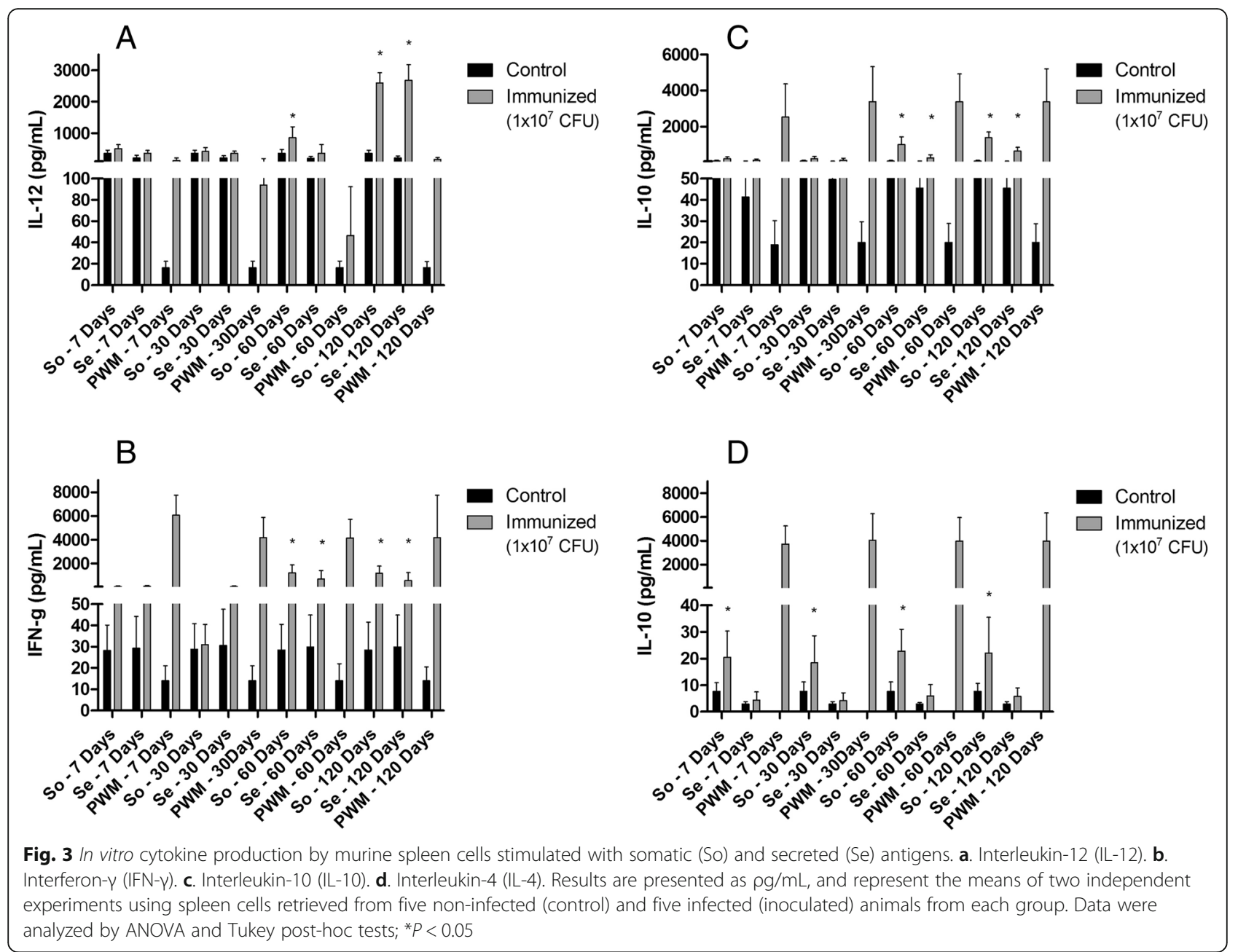

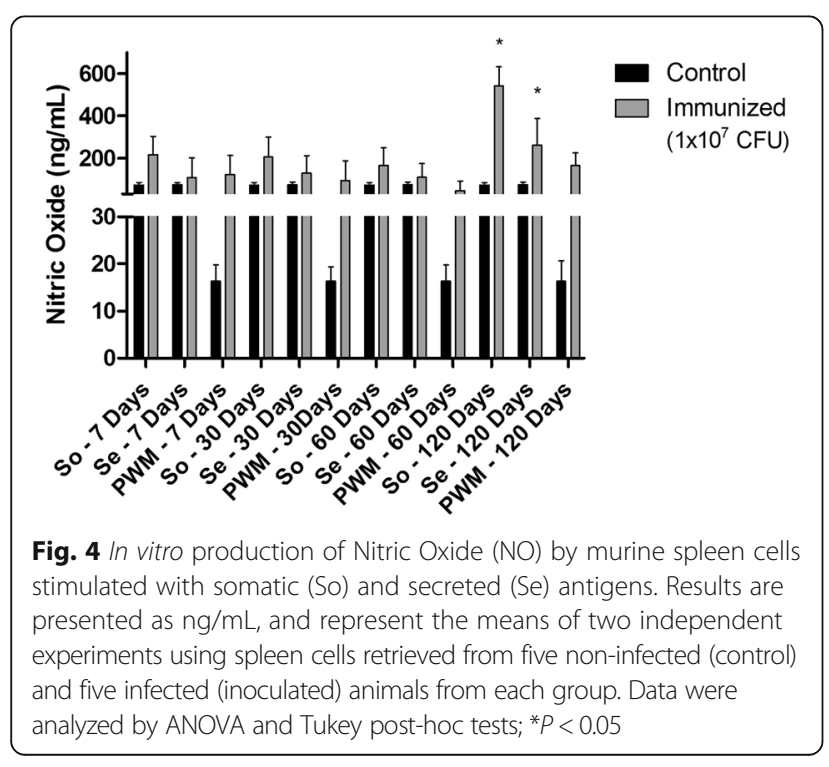

In addition, the cellular immune response is another way of reducing the dissemination of the pathogen, which can survive and multiply inside macrophages [7, 14, 18]. Accordingly, we found a significant production of IFN- $\gamma$ by spleen cells after stimulation with So or Se C. pseudotuberculosis antigens two months after inoculation. This situation was sustained until the end of the experiment (120 days). Elevated IL-4 production was not detected, yet, in cells stimulated with So, the production of this cytokine was four times higher in comparison to those stimulated with Se and controls. This phenomenon may possibly have occurred because So has a larger amount of structural proteins and lipid antigens than Se [31]. Relatedly, Lan et al. (1999) [19] found a pronounced increase in IFN- $\gamma$ production starting in the third week postinoculation in splenic cell cultures of ICR-JCL mice inoculated with ATCC 1940 strain and stimulated with formalin-killed bacterial cells, which was sustained until the eighth week. In the same experiment, no significant production of IL-4 was observed. 
IL-10 and IL-12 production by spleen cells stimulated by Se or So antigens increased post-inoculation time and was sustained at all time points evaluated. So was found to induce higher levels of IL-10 than Se, probably due the structural components of So, such as cytoplasm and membrane lipoproteins [31].

IL-10 may control IFN- $\gamma$ synthesis during infection, thereby avoiding Th1 over-reactivity [32]. On the other hand, IL-12 can also trigger mechanisms related to cell proliferation and IFN- $\gamma$ production [33]. Some studies have showed that IFN- $\gamma$, IL-10 and IL-12 are required to control persistent infections caused by intracellular parasites [34-36]. IL-12 is a cytokine crucial to Th1 shift, which is required to prevent the dissemination of pathogens within the host in order to control infection by facultative intracellular bacteria, such as C. pseudotuberculosis [14]. Accordingly, we found increased IL-12 production after 60 days, probably resulting from an immune response to reduce bacterial proliferation. Higher levels of IL-12 were detected at 120 days for both So and Se antigens, probably due to the persistence of infection. It is possible that, after this time, these levels would decrease as a result of IL-10 production.

NO production was also evaluated, due to its effectiveness in regulating the growth of intracellular pathogens [37]. Proteomic analysis has identified NO-responsive extracellular proteins of C. pseudotuberculosis and it also demonstrated the participation of the extracytoplasmic function sigma factor $\sigma^{\mathrm{E}}$ in composition of C. pseudotuberculosis exoproteome [38]. In the present studt, while NO production by spleen cells stimulated with So and Se antigens was higher at 120 days post-infection, So resulted in higher proliferations than Se, in accordance to what was observed in IFN- $\gamma$ and IL-10 production.

\section{Conclusion}

The attenuated T1 strain of C. pseudotuberculosis was found to induce both humoral and cellular immune responses in an experimental model of susceptible BALB/c mice. A $10^{7} \mathrm{CFU}$ dosage did not result in any lesions in the mice evaluated. As the present study has demonstrated that, in addition to the production of antibodies, an efficient cellular response is important to the control of CL, the T1 strain can be considered as a promising option for potential vaccine candidates.

\section{Methods}

\section{Bacterial strain}

The T1 strain of C. pseudotuberculosis was isolated from granulomas obtained from goats raised in the municipality of Juazeiro, located in the state of Bahia in northeastern Brazil. Isolates were stored in the Department of Microbiology collection center at the Health
Sciences Institute of the Federal University of Bahia (ICS - UFBA).

The identification of the T1 strain was confirmed by several microbiological methods: Gram staining, colony morphology, synergistic hemolytic (CAMP) reactions with Rhodococcus equi, urease and catalase production, as well as glucose and maltose fermentation. A commercial kit was used to aid in identification (API Coryne BioMérieux, Merci l'Etoile, France). Since the T1 strain demonstrated a less severe pattern of hemolysis during synergistic hemolysis testing in comparison to other wild strains, other authors have suggested its use as a vaccinal strain [39].

The T1 strain was cultivated in Brain/Heart Infusion (BHI) broth and incubated for $72 \mathrm{~h}$ at $37^{\circ} \mathrm{C}$. The bacterial suspension was washed in Phosphate Buffer Saline (PBS) and centrifuged for $30 \mathrm{~min}$ at $3,000 \mathrm{~g}$ at $4{ }^{\circ} \mathrm{C}$.

\section{Somatic antigen (So)}

The bacterial pellet was homogenized in PBS ( $\mathrm{pH} 7.4$ ) and sonicated at $60 \mathrm{~Hz}$ under $4{ }^{\circ} \mathrm{C}$ for five cycles lasting $60 \mathrm{~s}$ each (Branson Sonifier 450, Branson, Dunbury, CT, USA). The sample was centrifuged for $30 \mathrm{~min}$ at 10,000 $g$ and, after collection, the supernatant was stored at $-20{ }^{\circ} \mathrm{C}$ in aliquots until use. Protein concentration was determined by Lowry's modified method using a Bio-Rad Protein Assay (Bio-Rad, Hercules, CA, USA).

\section{Secreted antigen (Se)}

Se was obtained from the culture supernatant by saturation with $30 \%$ ammonium sulfate $(\mathrm{HCl}) \mathrm{pH} 4.0$ and nbutanol under slow agitation at room temperature. The sample was homogenized, left undisturbed for $60 \mathrm{~min}$, and then centrifuged for $10 \mathrm{~min}$ at $1,350 \mathrm{~g}$ under $4^{\circ} \mathrm{C}$. The resulting interphase was dissolved in $20 \mathrm{mM}$ of Tris buffer $\mathrm{pH} 7.4(500 \mu \mathrm{L}$ of buffer to $5 \mathrm{~mL}$ of culture supernatant), followed by dialysis in $50 \mathrm{mM}$ Phosphate buffer $\mathrm{pH} 7.4$ for $48 \mathrm{~h}$. The sample was concentrated by ultrafiltration with a $10 \mathrm{kDa}$ membrane (Millipore, Billerica, MA, USA). Protein concentration was determined by Lowry's modified method using a Bio-Rad Protein Assay (Bio-Rad, Hercules, CA, USA).

\section{Inoculation protocol and experimental design}

Prior to experimental inoculation, an optimal inoculation dose experiment was performed to obtain maximum antibody production. Eight-week-old male and female BALB/C mice, provided by the Experimental Animal Facility at the Gonçalo Moniz Research Center, Oswaldo Cruz Foundation, Salvador, Bahia-Brazil, were used to establish the inoculation protocol. The optimal dose was determined using five groups of five mice. Four groups received an intraperitoneal inoculation of $5 \times 10^{5}, 10^{6}, 5 \times 10^{6}$ and $10^{7}$ colony forming units (CFU) of 
C. pseudotuberculosis T1 strain diluted in sterile PBS at a final volume of $1 \mathrm{~mL}$. The control group received $1 \mathrm{~mL}$ of sterile PBS by intraperitoneal inoculation. Blood was collected from the tail vein and the animals used for dosage experimentation were euthanized in a $\mathrm{CO}_{2}$ chamber. ELISA was performed 120 days after inoculation to evaluate humoral immune response by identifying the highest levels of IgG and its subclasses.

After determining the optimal inoculation dosage, male and female $\mathrm{BALB} / \mathrm{c}$ mice received intraperitoneal inoculations with $10^{7} \mathrm{CFU} / \mathrm{mL}$ of $\mathrm{T} 1$ strain in $1 \mathrm{~mL}$ of sterile PBS, while the control group was inoculated with $1 \mathrm{~mL}$ of sterile PBS. After blood sampling from the tail vein, five animals from each group were euthanized in a $\mathrm{CO}_{2}$ chamber at 7, 30, 60 and 120 days after receiving inoculation. The animals' spleens were removed for splenocyte isolation in order to perform in vitro lymphocyte proliferation and cytokine production assays. Blood was also collected for immunoglobulin analysis.

\section{Indirect ELISA for analysis of IgG and its isotypes}

ELISA plates (Costar, Corning Life Sciences, Lowell, MA, USA) were coated with So $(1 \mu \mathrm{g}$ in $100 \mu \mathrm{L}$ of $50 \mathrm{mM}$ Carbonate-bicarbonate buffer $\mathrm{pH}$ 9.6, in each well), incubated overnight at $4{ }^{\circ} \mathrm{C}$ and washed twice in $0.05 \%$ PBS Tween-20 (PBS-T). Plates were then blocked with $200 \mu \mathrm{L}$ of $5 \%$ skim milk in $0.05 \%$ PBS-T and incubated for $2 \mathrm{~h}$ at $37{ }^{\circ} \mathrm{C}$. Next, the plates were washed once with PBS-T and $50 \mu \mathrm{L}$ of diluted serum (1:50 in $1 \%$ skim milk/PBS-T) was added to each well. Plates were then incubated for $1 \mathrm{~h}$ at $37{ }^{\circ} \mathrm{C}$ and washed five times with PBS-T. Next, wells were filled with $50 \mu \mathrm{L} /$ well of HRP conjugated rabbit Ig antimouse IgG (SigmaAldrich, St Louis, MO, USA) at a dilution of 1:10,000 in $1 \%$ skim milk/PBS-T to assess total IgG. To evaluate IgG1, IgG2a, IgG2b and IgG3, wells were filled with $50 \mu \mathrm{L} /$ well of HRP conjugated rabbit Ig antimouse IgG1, IgG2a, IgG2b or IgG3 (Zymed, San Francisco, CA, USA), respectively, each diluted at 1:8.000 in $1 \%$ skim milk/PBS-T. All plates were then incubated for $45 \mathrm{~min}$ at $37{ }^{\circ} \mathrm{C}$. Each plate was washed five times in PBS-T and $50 \mu \mathrm{L} /$ well of Citrate Phosphate Buffer $\mathrm{pH}$ 5.1, orthophenyl-diamine (Sigma, St Louis, MO, USA) and $30 \%$ $\mathrm{H}_{2} \mathrm{O}_{2}$ ] were added and left for $15 \mathrm{~min}$ at room temperature in a dark chamber. Reactions were stopped with $25 \mu \mathrm{L} /$ well of $4 \mathrm{~N} \mathrm{H}_{2} \mathrm{SO}_{4}$ and Optical Density (OD) was measured at $490 \mathrm{~nm}$ using an ELISA Plate Reader (BIORAD, Hercules, CA, USA).

\section{Lymphocyte proliferation assay}

The spleen of each mouse was removed, washed three times with Hanks' solution, and then placed in a petri dish containing $5 \mathrm{~mL}$ of RPMI 1640 medium (Gibco Laboratories, North Andover, MA, USA) supplemented with penicillin and streptomycin. The spleens were then macerated and the cellular suspension was transferred to a conical tube containing $5 \mathrm{~mL}$ of the same medium, followed by centrifugation at $400 \mathrm{~g}$ for $3 \mathrm{~min}$. Pellets were resuspended in $0.17 \mathrm{M}$ of $\mathrm{NH}_{4} \mathrm{Cl}$ for $5 \mathrm{~min}$ at $4{ }^{\circ} \mathrm{C}$ in order to lyse erythrocytes. Cells were washed 3 times with RPMI and then resuspended in RPMI enriched with $10 \%$ bovine fetal serum.

Cell viability was determined by a Trypan Blue exclusion assay. $10^{6}$ cells $/ \mathrm{mL}$ were cultivated in 96-well microculture plates in RPMI-1640 medium supplemented with L-glutamine, penicillin/streptomycin, gentamicin and $10 \%$ fetal calf serum. Cells were stimulated by So or Se C. pseudotuberculosis antigens $(40 \mu \mathrm{g} / \mathrm{mL})$, and pokeweed mitogen $(2.5 \mu \mathrm{g} / \mathrm{mL})$ was used as a positive control, while medium alone was used as a negative control. All plates were incubated for $120 \mathrm{~h}$ at $37^{\circ} \mathrm{C}$ under $5 \%$ $\mathrm{CO}_{2} .1 \mu \mathrm{Bq} /$ well $(10 \mu \mathrm{L})$ of fresh $\left[{ }^{3} \mathrm{H}\right]$ thymidine (GE Healthcare, Bucks, UK) was added $18 \mathrm{~h}$ prior to the end of the incubation time using a beta counter system (iMatic Canberra, Meriden, USA). After $120 \mathrm{~h}$, plates were frozen at $-20{ }^{\circ} \mathrm{C}$ and $\beta$-radiation was measured as described by Paule et al. (2004) [23]. Results are expressed in terms of a Stimulation Index (SI), calculated by dividing the $\beta$ radiation found for each stimulated sample by the radiation measured from its respective negative control.

\section{ELISA for cytokines quantification}

Cytokine analysis was performed in a culture supernatant obtained from cells $\left(10^{6} / \mathrm{mL}\right)$ cultivated in the same medium used for lymphoproliferation assay. Spleen cells were stimulated with So and Se C. pseudotuberculosis antigens $(40 \mu \mathrm{g} / \mathrm{mL})$, pokeweed mitogen $(2,5 \mu \mathrm{g} / \mathrm{mL})$ as a positive control, and the medium alone (negative control). The plates were incubated for $120 \mathrm{~h}$ at $37^{\circ} \mathrm{C}$ in $5 \% \mathrm{CO}_{2}$ [40]. The supernatant was collected, centrifuged, and kept at $-20^{\circ} \mathrm{C}$ until use.

Cytokine profile analysis was performed using commercial kits for IFN- $\gamma$ and IL-10 (R\&D Systems, Minneapolis, MN, USA), and IL-12 and IL-4 (Pharmigen, San Jose, CA, USA) according to the manufacturer instructions. Results are expressed in $\rho g / \mathrm{mL}$.

\section{Nitric oxide (NO) production assay}

The presence of NO in the supernatant of spleen cells cultures that were incubated for $120 \mathrm{~h}$ was measured by nitrite assay, based on Griess reaction [41]. Briefly, supernatant $(50 \mu \mathrm{L})$ was mixed with $50 \mu \mathrm{L}$ of Griess reagent ( $1 \%$ sulfanilamide and $0.1 \% \mathrm{~N}$-(1-naphthyl)ethylenediamine, in $5 \%$ phosphoric acid) and incubated for $10 \mathrm{~min}$ at room temperature. Absorbances were measured at $492 \mathrm{\eta m}$ using an ELISA microplate reader (BioRad, Hercules, CA, USA). The standard curve of $\mathrm{NO}_{2}^{-}$was prepared by diluting nitrite stock solution (1 $\mathrm{M} \mathrm{NaNO}_{2}$ 
diluted in Milli-Q water) in spleen cell culture media. Results are expressed in $\eta \mathrm{g} / \mathrm{mL}$.

\section{Statistical analysis}

For determination of statistical significance between experimental groups at an individual time-point, a analysis of variance (ANOVA) was performed using SPSS 12.0. (IBM Statistics, Chicago, EUA). A $p$ value of $<0.05$ was considered significant.

\section{Acknowledgements}

Authors are sincerely grateful to the technical staff of the LABIMUNO/ICS for their assistance.

\section{Funding}

This study was supported by Laboratory of Immunology of Health Sciences Institute of Federal University of Bahia (Laboratório de Imunologia do Instituto de Ciências da Saúde da Universidade Federal da Bahia - LABIMUNO/ICS/UFBA) and by the Scientific and Technological Development Fund (Fundo de Desenvolvimento Científico e Tecnológico - FUNDECI) of Banco do Nordeste do Brasil S. A. (BNB).

\section{Availability of data and materials}

All the data supporting these findings is contained within the manuscript.

\section{Authors' contributions}

MCS, APS and EJM carried out the immunoassays. HSPC and LFMC carried out the microbiological experiments. BJAP and SCT participated in the design of the study and performed the statistical analysis. EKNSL and ILON helped to draft the manuscript. VLCV and RJMN conceived of the study and participated in its design and coordination. All authors read and approved the final manuscript.

\section{Competing interests}

The authors declare that they have no competing interests.

\section{Consent for publication}

Not applicable.

\section{Ethics approval and consent to participate}

This study is in agreement with the Ethical Principles for Animal Research established by Brazilian Society of Laboratory Animal Science (SBCAL), and was approved by the Institutional Review Board for Animal Research of the Institute of Health Sciences (CEUA - ICS) at the Federal University of Bahia (UFBA), Salvador-Brazil.

\section{Author details}

'Department of Exact and Earth Sciences, State University of Bahia, Campus II, Alagoinhas, BA CEP 48110-100, Brazil. ' ${ }^{2}$ Department of Biointeraction, Federal University of Bahia, Av. Reitor Miguel Calmon s/n, Vale do Canela, Salvador, BA CEP 40110-100, Brazil. ${ }^{3}$ Department of Health, Feira de Santana State University, Avenida Transnordestina s/n, Novo Horizonte, Feira de Santana, BA CEP 44036-900, Brazil. ${ }^{4}$ Department of Life Sciences, State University of Bahia, Rua Silveira Martins 2555, Cabula, Salvador, BA CEP 41150-000, Brazil. ${ }^{5}$ Immunology and Molecular Biology Laboratory, Health Sciences Institute, Federal University of Bahia, Av. Reitor Miguel Calmon s/n Vale do Canela, Salvador, BA CEP 40110-100, Brazil.

Received: 3 August 2015 Accepted: 30 August 2016

Published online: 08 September 2016

\section{References}

1. Unanian MM, Feliciano Silva AE, Pant KP. Abscesses and caseous lymphadenitis in goats in tropical semi-arid north-east Brazil. Trop Anim Health Prod. 1985;17:57-62.

2. Guimarães AS, Carmo FB, Heinemann MB, Portela RW, Meyer R, Lage AP, et al. High sero-prevalence of caseous lymphadenitis identified in slaughterhouse samples as a consequence of deficiencies in sheep farm management in the state of Minas Gerais, Brazil. BMC Vet Res. 2011;7:68.
3. Bastos BL, Dias Portela RW, Dorella FA, Ribeiro D, Seyffert N, Castro TLP, et al. Corynebacterium pseudotuberculosis: immunological responses in animal models and zoonotic potential. J Clin Cell Immunol. 2012;\$4:005.

4. Costa MP, McCulloch JA, Almeida SS, Dorella FA, Fonseca CT, Oliveira DM, et al. Molecular characterization of the Corynebacterium pseudotuberculosis hsp60-hsp10 operon, and evaluation of the immune response and protective efficacy induced by hsp60 DNA vaccination in mice. BMC Res Notes. 2011:4:243.

5. Bastos BL, Loureiro D, Raynal JT, Guedes MT, Vale VL, Moura-Costa LF, et al. Association between haptoglobin and IgM levels and the clinical progression of caseous lymphadenitis in sheep. BMC Vet Res. 2013;9:254.

6. Batey RG. Pathogenesis of caseous lymphadenitis in sheep and goats. Aust Vet J. 1986:63:269-72.

7. McKean S, Davies J, Moore R. Identification of macrophage induced genes of Corynebacterium pseudotuberculosis by differential fluorescence induction. Microbes Infect. 2005;7:1352-63.

8. Ruiz JC, D'Afonseca V, Silva A, Ali A, Pinto AC, Santos AR, et al. Evidence for reductive genome evolution and lateral acquisition of virulence functions in two Corynebacterium pseudotuberculosisstrains. PLoS ONE. 2011;6:e18551.

9. Batey RG. Aspects of pathogenesis in a mouse model of infection by Corynebacterium pseudotuberculosis. Aust J Exp Biol Med Sci. 1986:64:237-49.

10. Soares SC, Silva A, Trost E, Blom J, Ramos R, Carneiro A, et al. The pangenome of the animal pathogen Corynebacterium pseudotuberculosis reveals differences in genome plasticity between the biovar ovis and equi strains. PLOS ONE. 2013:8:e53818.

11. Pacheco LGC, Slade SE, Seyffert N, Santos AR, Castro TLP, Silva WM, et al. A combined approach for comparative exoproteome analysis of Corynebacterium pseudotuberculosis. BMC Microbiol. 2011;11:12.

12. Dorella FA, Gala-Garcia A, Pinto AC, Sarrouh B, Antunes CA, Ribeiro D, et al. Progression of "OMICS" methodologies for understanding the pathogenicity of Corynebacterium pseudotuberculosis: the Brazilian experience. Comput Struct Biotechnol J. 2013:6:e201303013.

13. Cameron CM, Engelbrecht MM. Mechanism of immunity to Corynebacterium pseudotuberculosis (Buchanan, 1911) in mice using inactivated vaccine. Onderstepoort J Vet Res. 1971;38:73-82.

14. Pépin M, Seow HF, Corner L, Rothel JS, Hodgson AL, Wood PR. Cytokine gene expression in sheep following experimental infection with various strains of Corynebacterium pseudotuberculosis differing in virulence. Vet Res. 1997:28:149-63.

15. de Souza AP, Vale VLC, Silva MC, Araújo IBO, Trindade SC, Moura-Costa LF, et al. MAPK involvement in cytokine production in response to Corynebacterium pseudotuberculosis infection. BMC Microbiol. 2014;14:230.

16. Ellis JA, Lairmore MD, Otoole D, Campos M. Differential induction of Tumor Necrosis Factor Alpha in ovine pulmonary alveolar macrophages following infection with Corynebacterium pseudotuberculosis, Pasteurella haemolytica, or Lentiviruses. Infect Immun. 1991;59:3254-60.

17. Ellis JA, Russell HI, Du CW. Effect of selected cytokines on the replication of Corynebacteriurn pseudotuberculosis and ovine lentiviruses in pulmonary macrophages. Vet Immunol Immunopathol. 1994:40:31-47.

18. Lan DT, Taniguhi S, Makino S, Shirahata N, Nakane A. Role of endogenous Tumor Necrosis Factor Alpha and Gamma Interferon in resistance to Corynebacterium pseudotuberculosis infection in mice. Microbiol Immunol. 1998;42:863-70

19. Lan DT, Makino SI, Shirahata T, Yamada M, Nakane A. Tumor necrosis factor alpha and gama interferon are required for the development of protective immunity to secondary Corynebacterium pseudotuberculosis infection in mice. J Vet Med Sci. 1999:11:1203-8.

20. Flynn JL, Chan J, Triebold KJ, Dalton DK, Stewart TA, Bloom BR. An essential role for Interferon gamma in resistance to Mycobacterium tuberculosis infection. J Exp Med. 1993;178:2249-54.

21. El-Enbaawy MI, Saad MM, Selim SA. Humoral and cellular immune responses of a murine model against Corynebacterium pseudotuberculosis antigens. Egypt J Immunol. 2005;12:13-9.

22. Paule BJ, Azevedo V, Regis LF, Carminati R, Bahia CR, Vale VL, et al. Experimental Corynebacterium pseudotuberculosis primary infection in goats: kinetics of lgG and interferon-gamma production, lg G avidity and antigen recognition by Western blotting. Vet Immunol Immunopathol. 2003;96:129-39.

23. Paule BJ, Meyer R, Moura-Costa LF, Bahia RC, Carminati R, Regis LF, et al. Three-phase partitioning as an efficient method for extraction / concentration of immunoreactive excreted-secreted proteins of Corynebacterium pseudotuberculosis. Protein Expr Purif. 2004;34:311-16. A. 
24. Meyer R, Regis L, Vale V, Paule B, Carminati $R$, Bahia $R$, et al. In vitro IFNgamma production by goat blood cells after stimulation with somatic and secreted Corynebacterium pseudotuberculosis antigens. Vet Immunol Immunopathol. 2005;107:249-54.

25. Huygen K, Palfliet K. Strain variation in interferon gamma production of BCGsensitized mice challenged with PPD II. Importance of one major autosomal locus and additional sexual influences. Cell Immunol. 1984;85:75-81.

26. Oswald IP, Afroun S, Bray D, Petit JF, Lemaire G. Low response of BALB/C macrophages to priming and activating signals. J Leukoc Biol. 1992;52:315-22.

27. Tumitan AR, Monnazzi LG, Ghiraldi FR, Cilli EM. Machado de Medeiros BM. Pattern of macrophage activation in yersinia-resistant and yersiniasusceptible strains of mice. Microbiol Immunol. 2007;51:1021-8.

28. Muckle CA, Menzies PI, Li Y, Hwang YT, van Wesenbeeck M. Analysis of the immunodominant antigens of Corynebacterium pseudotuberculosis. Vet Microbiol. 1992:30:47-58

29. Eggleton DG, Haynes JA, Middleton HD, Cox JC. Immunisation against ovine caseous lymphadenitis: correlation between Corynebacterium pseudotuberculosis toxoid content and protective efficacy in combined clostridial-corynebacterial vaccines. Aust Vet J. 1991;68:322-5.

30. Hodgson AL, Tachedjian M, Corner LA, Radford AJ. Protection of sheep against caseous lymphadenitis by use of a single oral dose of live recombinant Corynebacterium pseudotuberculosis. Infect Immun. 1994;62: 5275-80.

31. Paule BJA, Azevedo V, Moura-Costa LF, Freire SM, Regis LF, Vale VLC, et al. SDS-PAGE and Western blot analysis of somatic and extracellular antigens of Corynebacterium pseudotuberculosis. Rev Ciênc Méd Biol. 2004:3:44-52.

32. Pestka S, Krause CD, Sarkar D, Walter MR, Shi Y, Fisher PB. Interleukin-10 and related cytokines and receptors. Annu Rev Immunol. 2004;22:929-79.

33. Trinchieri G, Scott P. Interleukin-12: a proinflammatory cytokine with immunoregulatory functions. Res Immunol. 1995;146:423-31.

34. Pohl-Koppe A, Balashov KE, Steere AC, Logigian EL, Hafler DA. Identification of a T cell subset capable of both IFN- $\gamma$ and IL-10 secretion in patients with chronic Borrelia burgdorferi infection. J Immunol. 1998;160:1804-10.

35. Trinchieri $G$. Regulatory role of $T$ cells producing both interferon gamma and interleukin 10 in persistent infection. J Exp Med. 2001;194:F53-7.

36. Fortune SM, Solache A, Jaeger A, Hill PJ, Belisle JT, Bloom BR, et al. Mycobacterium tuberculosis inhibits macrophage responses to IFN- $\gamma$ through myeloid differentiation factor 88-dependent and -independent mechanisms. J Immunol. 2004;172:6272-80.

37. Green SJ, Nacy CA, Meltzer MS. Cytokine-induced synthesis of nitrogen oxides in macrophages: a protective host response to Leishmania and other intracellular pathogens. J Leukoc Biol. 1991;50:93-103.

38. Pacheco LGC, Castro TLP, Carvalho RD, Moraes PM, Dorella FA, Carvalho NB, et al. A role for sigma factor $\sigma^{E}$ in Corynebacterium pseudotuberculosis resistance to nitric oxide / peroxide stress. Front Microbiol. 2012;3:126.

39. Moura-Costa LF, Bahia RC, Carminati R, Vale VL, Paule BJ, Portela RW, et al. Evaluation of the humoral and cellular immune response to different antigens of Corynebacterium pseudotuberculosis in Canindé goats and their potential protection against caseous lymphadenitis. Vet Immunol Immunopathol. 2008;126:131-41.

40. Salas-Téllez E, Núñez del Arco A, Tenorio V, Díaz-Aparicio E, de la Garza M, Suárez-Güemes F. Subcellular fractions of Brucella ovis distinctively induce the production of interleukin-2, interleukin-4, and interferon-gamma in mice. Can J Vet Res. 2005;69:53-7.

41. Green LC, Wagner DA, Glogowski J, Skipper PL, Wishnok JS, Tannenbaun SR Analysis of nitrite and $\left({ }^{15} \mathrm{~N}\right)$ nitrate in biological fluids. Anal Biochem. 1982; 126:131-8.

\section{Submit your next manuscript to BioMed Central and we will help you at every step:}

- We accept pre-submission inquiries

- Our selector tool helps you to find the most relevant journal

- We provide round the clock customer support

- Convenient online submission

- Thorough peer review

- Inclusion in PubMed and all major indexing services

- Maximum visibility for your research

Submit your manuscript at www.biomedcentral.com/submit 